\title{
DESIGN AND OPTIMIZATION OF MICROPARTICULATE RESERVOIR MATRICES FOR COMBINATION THERAPY
}

\author{
MANISH YADAV \\ SGT College of Pharmacy, SGT University, Gurugram, Haryana, India \\ Email: manish.yadav@sgtuniversity.org \\ Received: 12 Dec 2019, Revised and Accepted: 28 Feb 2020
}

\begin{abstract}
Objective: The purpose of this investigation was to design and develop controlled release floating beads of Ketoprofenand Pantoprazole sodium. To determine the interaction between excipients used and to find out the nature of drug in the formulation, X-ray diffraction (XRD) and Differential Scanning Colorimetry (DSC) studies were performed.

Methods: The beads were prepared by ionotropic gelation technique. Sodium alginate and HPMC E5LV was dissolved in deionized water (9:1 sodium alginate: HPMC E5LV) at a concentration of 1-3 \% w/v using gentle heat on the water bath. After getting a clear solution, an accurately weighed quantity of Pantoprazole sodium was added and dispersed uniformly into the solution. In a separate beaker, Ketoprofen and calcium carbonate $\left(1: 1\right.$, Sodium alginate: $\left.\mathrm{CaCl}_{2}\right)$ was dispersed in water and mixed with sodium alginate solution containing Pantoprazole sodium. The bubble-free sodium alginate-drug dispersion $(20 \mathrm{ml})$ was added dropwise via a 22-guage hypodermic needle fitted with a $10 \mathrm{ml}$ syringe into $100 \mathrm{ml}$ of calcium chloride solution (1-2\% w/v) containing $10 \%$ glacial acetic acid and stirred at $400 \mathrm{rpm}$ for $15 \mathrm{~min}$
\end{abstract}

Results: From the experimental study, it was concluded that optimized batch F9 showed good micromeritic properties, entrapment efficiency and releases the drug slowly and completely for $12 \mathrm{~h}$ as beads remain in floating condition throughout dissolution study that assures prepared formulation remain floated in the stomach without its early passing to lower Gastro-Intestinal Tract(GIT) side. The percentage of drugs release of Ketoprofen and Pantoprazole Sodium was $96.56 \%$ and $97.74 \%$, respectively at $12 \mathrm{~h}$.

Conclusion: Combination of different polymer provide sustained release pattern in different concentration. Formulation F9 gives good floating behavior using sodium alginate and HPMC hydroxypropyl methylcellulose in different ratios. In the present study, a satisfactory attempt has been made to formulate gastro retentive floating beads of Ketoprofen and Pantoprazole sodium.

Keywords: Anti-inflammatory, Ketoprofen, Pantoprazole sodium, Alginate beads, Ionotropic gelation

(C) 2020 The Authors. Published by Innovare Academic Sciences Pvt Ltd. This is an open access article under the CC BY license (http://creativecommons.org/licenses/by/4.0/) DOI: http://dx.doi.org/10.22159/ijap.2020v12i3.36614. Journal homepage: https://innovareacademics.in/journals/index.php/ijap

\section{INTRODUCTION}

Gastro Retentive Drug Delivery (GRDD) devices are primarily sitespecific drug delivery systems, which gets retained in the stomach for a longer period of time, thus helping in the absorption of drug for the intended duration of time $[1,2]$. Floating Drug Delivery System (FDDS) reside in the stomach for a longer period of time than conventional dosage forms after the release of drugs; the residual system is emptied from the stomach [3]. The contribution of floating drug delivery system includes; gastric retention time is increased because of buoyancy, site-specific drug delivery to stomach [4]. The real challenge in the development of an oral controlled-release drug delivery system is not just to sustain the drug release but also to prolong the presence of the dosage form within the Gastro-Intestinal Tract (GIT) until all the drugs is completely released at the desired period of time [5]. To overcome these limitations, various gastroretentive systems have been designed to be retained in the gastric region for a prolonged time. These systems include a) Floating systems, b) Bioadhesive systems, c) Swelling and expanding systems, d) High-density systems, e) Modified systems [6]. The antiinflammatory effects of Ketoprofen are believed to be due to inhibition of cyclooxygenase-2(COX-2), an enzyme involved in prostaglandin synthesis via the arachidonic acid pathway.
Ketoprofen is a non-specific cyclooxygenase inhibitor, and inhibition of cyclooxygenase-2 (COX-2) is thought to confer some of its side effects, such as GI upset and ulceration. Pantoprazole sodium is a Proton Pump Inhibitor (PPI) that suppresses the final step in gastric acid production by covalently binding to the $\left(\mathrm{H}^{+}, \mathrm{K}^{+}\right)$ATPase enzyme system at the secretory surface of the gastric parietal cell. This effect leads to inhibition of both basal and stimulated gastric acid secretion, irrespective of the stimulus. The binding to the $\left(\mathrm{H}^{+}, \mathrm{K}^{+}\right)$ ATPase results in a duration of antisecretory effect that persists longer than $12 \mathrm{~h}$. for all doses tested. Response Surface Methodology (RSM) as a tool of designing of experiments is a widely practiced approach in the development and optimization of drug delivery devices [7-12]. The technique requires minimum experimentation and less time.

\section{MATERIALS AND METHODS}

Materials

Ketoprofen and pantoprazole sodium were provided by Milan Laboratories (India) Pvt. Ltd. Maharashtra. Sodium alginate, hydroxypropyl methylcellulose (HPMC) and calcium chloride were obtained from MolyChem Thane-421503 (India) and all other ingredients used were of pharmaceutical grade.

Table 1.1: Trial batches of formulation

\begin{tabular}{|c|c|c|c|c|c|c|c|}
\hline \multirow[t]{2}{*}{ Formulation code } & Sodium alginate & Calcium chloride & \multirow[t]{2}{*}{ HPMC K15M, } & \multirow[t]{2}{*}{ HPMC К4M } & \multirow[t]{2}{*}{ HPMC E5LV } & \multirow[t]{2}{*}{ HPMC E6LV } & \multirow[t]{2}{*}{ HPMC K100 } \\
\hline & $(\% \mathrm{w} / \mathrm{v})$ & $(\% \mathrm{w} / \mathrm{v})$ & & & & & \\
\hline C1 & 2 & 2 & 1 & - & - & - & - \\
\hline $\mathrm{C} 2$ & 2 & 2 & - & 1 & - & - & - \\
\hline $\mathrm{C} 3$ & 2 & 2 & - & - & 1 & - & - \\
\hline $\mathrm{C} 4$ & 2 & 2 & - & - & - & 1 & - \\
\hline $\mathrm{C} 5$ & 2 & 2 & - & - & - & - & 1 \\
\hline
\end{tabular}

Pantoprazole Sodium (40 mg) and Ketoprofen (100 mg) was used in all the above formulations 
Methods: Preparation of drug-loaded beads by manual syringe method

The beads were prepared according to the composition presented in table 1.1. Sodium alginate was dissolved in distilled water at $60^{\circ} \mathrm{C}$ in a water bath for 1 hour in order to obtain a clear polymer solution with a concentration of $2 \%(\mathrm{w} / \mathrm{w})$. Different grade of HPMC was dispersed in the alginate solution. Cooldown the solution at room temperature and Pantoprazole Sodium and Ketoprofen was added with continued stirring with a glass rod in a bath sonicator. Accordingly, $10 \mathrm{ml}$ syringes fitted with a needle having a size of $22 \mathrm{G}$ were employed in the preparation of all formulation. Above solution was introduced dropwise into the gelling solution $(2 \% \mathrm{w} / \mathrm{v})$ aqueous calcium chloride while being gently stirred at $25^{\circ} \mathrm{C}$. The stirring was continued for $15 \mathrm{~min}$ and the calcium alginate beads were harvested by filtration.

\section{Formulation of floating beads}

The beads were prepared by ionotropic gelation technique. Sodium alginate and HPMC E5LV was dissolved in deionized water $9: 1$ sodium alginate: HPMC E5LV) at a concentration of 1-3 \% w/v using gentle heat on a water bath. After getting a clear solution, an accurately weighed quantity of Pantoprazole sodium was added and dispersed uniformly into the solution. In a separate beaker, Ketoprofen and calcium carbonate $\left(1: 1\right.$, Sodium alginate: $\left.\mathrm{CaCl}_{2}\right)$ was dispersed in water and mixed with sodium alginate solution containing Pantoprazole sodium. The bubble-free sodium alginatedrug dispersion $(20 \mathrm{ml})$ was added dropwise via a 22-guage hypodermic needle fitted with a $10 \mathrm{ml}$ syringe into $100 \mathrm{ml}$ of calcium chloride solution (1-2 \% w/v) containing $10 \%$ glacial acetic acid and stirred at $400 \mathrm{rpm}$ for $15 \mathrm{~min}$. The droplets from the dispersion instantaneously gelled into discrete matrices upon contact with the solution of the gelling agent. Finally, beads were filtered, washed and dried at room temperature. For bead formation,
$20 \mathrm{ml}$ of a $1-3 \% \mathrm{w} / \mathrm{v}$ aqueous solution of sodium alginate containing Pantoprazole sodium and Ketoprofen was introduced dropwise from a glass syringe with a size- 22 needle into $100 \mathrm{ml}$ of an aqueous $2 \% \mathrm{~W} / \mathrm{V}$ calcium chloride solution being stirred at $400 \mathrm{rpm}$. The stirring was continued for one hour and the calcium alginate beads were harvested by filtration, washed with distilled water, and airdried overnight [13].

\section{Experimental design}

A number of preliminary trials were conducted before the application of the design as shown above. The levels of the factors were also determined randomly by evaluating the dependent variables (responses) of trial batches. A $3^{2}$ factorial design was used for optimizing the formulations using Design-Expert Software (Version-8.0.7.1). The concentration of sodium alginate (X1) and the concentration of calcium chloride (X2) were classified as low, medium and high values for independent variables as given in table 1.2. These studied factors along with their levels and the corresponding responses are summarized in table 1.3.

\section{Methods}

A response surface method $3^{2}$ factorial designs were applied to evaluate the relationship between the independent variables and their responses. Two variables and one response were involved in the experimental design. The dependent response factor variables measured were entrapment efficiency and \% Floating. The independent variables are the concentration of alginate (X1) and the concentration of calcium chloride (X2). The formulation variables and the high and low levels of each variable were defined based on preliminary experiments. Center points were repeated three times to estimate the experimental error. The independent and dependent variables are shown in table and process variables and their levels for full-factorial design are given in table.

Table 1.2: Various independent and dependent variables

\begin{tabular}{lll}
\hline S. No. & Independent variables & Dependent variables \\
\hline 1 & X1-Sodium alginate concentration $(\% \mathrm{~W} / \mathrm{V})$ & Y1-\%Entrapment efficiency \\
2 & X2-Concentration of calcium chloride $(\% \mathrm{~W} / \mathrm{V})$ & Y2-\% Floating \\
\hline
\end{tabular}

Table 1.3: Process variables and their levels for full-factorial design

\begin{tabular}{llll}
\hline S. No. & Factors & Low level & Middle level \\
\hline 1 & Concentration of Sodium alginate $(\% \mathrm{~W} / \mathrm{V})$ & 1 & 2 \\
2 & Concentration of Calcium chloride $(\% \mathrm{~W} / \mathrm{V})$ & 1 & 3 \\
\hline
\end{tabular}

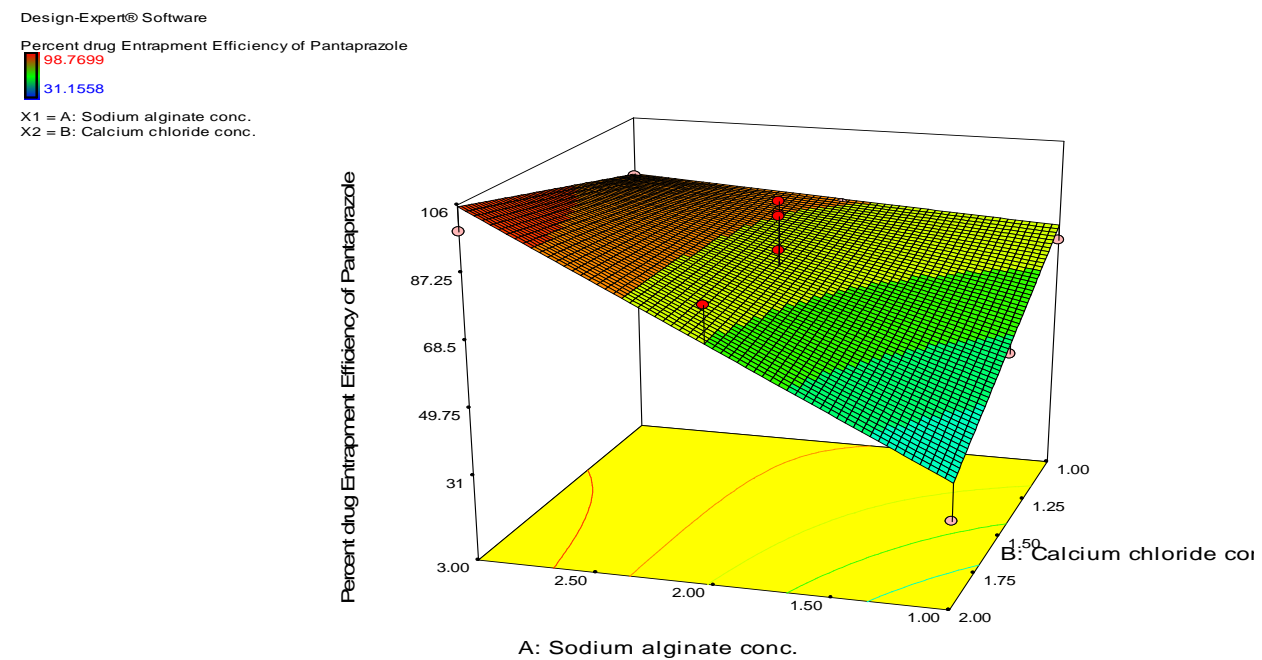

Fig. 1.1: Percentage drug entrapment efficacy pantoprazole sodium 


\section{RESULTS AND DISCUSSION}

Table 1.4: Evaluation parameters of different floating alginate beads

\begin{tabular}{|c|c|c|c|c|c|}
\hline \multirow[t]{2}{*}{ Formulation code } & \multirow[t]{2}{*}{$\%$ Yield } & \multicolumn{2}{|l|}{ \% Entrapment efficiency } & \multirow[t]{2}{*}{ \% Floating } & \multirow[t]{2}{*}{ Physical appearance } \\
\hline & & Pantoprazole sodium (PTS) & Ketoprofen (KT) & & \\
\hline $\mathrm{C} 1$ & $86.35 \pm 0.12$ & $63.16 \pm 0.41$ & $36.26 \pm 0.23$ & $20 \pm 0.16$ & Oval \\
\hline $\mathrm{C} 2$ & $76.75 \pm 0.32$ & $66.99 \pm 0.31$ & $38.39 \pm 0.34$ & $25 \pm 0.33$ & Oval \\
\hline C3 & $81.89 \pm 0.30$ & $97.29 \pm 0.13$ & $91.27 \pm 0.43$ & $55 \pm 0.28$ & Round \\
\hline $\mathrm{C} 4$ & $77.97 \pm 0.16$ & $77.37 \pm 0.22$ & $73.29 \pm 0.31$ & $30 \pm 0.34$ & Round \\
\hline $\mathrm{C} 5$ & $78.37 \pm 0.34$ & $73.92 \pm 0.17$ & $70.29 \pm 0.25$ & $27 \pm 0.33$ & Oval \\
\hline
\end{tabular}

Data from each response is presented in mean \pm SD $(n=3)$

Among of the above formulations (trial batches), formulation C3 having Hydroxy Propyl Methyl Cellulose [HPMC] E5LV polymer shows good entrapment efficiency $97.29 \%$ and $91.27 \%$ for
Pantoprazole Sodium and Ketoprofen respectively. Round appearance but buoyancy is not good so the different ratio of calcium chloride was tried for better buoyancy.

Table 1.5: Experimental design and results for the various measured responses of Pantoprazole Sodium and Ketoprofen beads

\begin{tabular}{|c|c|c|c|c|c|c|c|c|}
\hline \multirow[t]{2}{*}{ Run } & \multicolumn{3}{|l|}{ Variables } & \multicolumn{3}{|l|}{ Response } & \multirow[t]{2}{*}{$\%$ Yield } & \multirow[b]{2}{*}{$\begin{array}{l}\text { Physical } \\
\text { appearance }\end{array}$} \\
\hline & $\begin{array}{l}\text { Formulation } \\
\text { code }\end{array}$ & $\begin{array}{l}\text { SA Conc. (\% } \\
W / V)(X 1)\end{array}$ & $\begin{array}{l}\text { Cal. C Conc. } \\
(W / V)(X 2)\end{array}$ & $\begin{array}{l}\text { \% Drug EE } \\
\text { (PTS) }\end{array}$ & \% Drug EE (KT) & $\begin{array}{l}\% \\
\text { Floating }\end{array}$ & & \\
\hline 1 & F1 & 1 & 2 & $31.15 \pm 0.19$ & $23.63 \pm 0.21$ & $65 \pm 0.32$ & $44.40 \pm 0.32$ & Irregular \\
\hline 2 & $\mathrm{~F} 2$ & 2 & 1.5 & $95.85 \pm 0.37$ & $74.48 .93 \pm 0.16$ & $97 \pm 0.21$ & $58.94 \pm 0.22$ & Round \\
\hline 3 & F3 & 3 & 2 & $98.76 \pm 0.31$ & $68.20 \pm 0.22$ & $95 \pm 0.42$ & $47.6 \pm 0.25$ & Oval with tailing \\
\hline 4 & F4 & 2 & 1.5 & $93.72 \pm 0.26$ & $63.62 \pm 0.17$ & $98 \pm 0.22$ & $46.6 \pm 0.13$ & Round \\
\hline 5 & F5 & 1 & 1.5 & $58.58 \pm 0.32$ & $40.67 \pm 0.19$ & $85 \pm 0.31$ & $37.28 \pm 0.27$ & Irregular \\
\hline 6 & F6 & 2 & 1.5 & $93.17 \pm 0.21$ & $56.06 \pm 0.16$ & $95 \pm 0.24$ & $32.69 \pm 0.25$ & Round \\
\hline 7 & F7 & 2 & 1.5 & $55.47 \pm 0.41$ & $64.14 \pm 0.18$ & $97 \pm 0.11$ & $47.78 \pm 0.26$ & Round \\
\hline 8 & F8 & 3 & 1.5 & $86.51 \pm 0.34$ & $62.01 \pm 0.23$ & $100 \pm 0.32$ & $47.11 \pm 0.23$ & Oval with tailing \\
\hline 9 & F9 & 2 & 1 & $97.74 .18 \pm 0.15$ & $96.5763 .66 \pm 0.18$ & $95 \pm 0.20$ & $46.63 \pm 0.26$ & Round \\
\hline 10 & F10 & 2 & 1.5 & $83.48 \pm 0.15$ & $70.76 \pm 0.22$ & $85 \pm 0.14$ & $46.15 \pm 0.19$ & Round \\
\hline 11 & F11 & 3 & 1 & $87.96 \pm 0.26$ & $70.81 \pm 0.35$ & $96 \pm 0.23$ & $39.32 \pm 0.16$ & Rod Shaped \\
\hline 12 & F12 & 1 & 1 & $76.37 \pm 0.14$ & $65.65 \pm 0.16$ & $95 \pm 0.41$ & $39.49 \pm 0.31$ & Irregular \\
\hline 13 & F13 & 2 & 2 & $84.01 \pm 0.31$ & $65.60 \pm 0.17$ & $100 \pm 0.22$ & $57.98 \pm 0.25$ & Round \\
\hline
\end{tabular}

Data from each response is presented in mean $\pm \mathrm{SD}(\mathrm{n}=3)$, 3D Surface Response Graph between Sodium alginate $\left(\mathrm{X}_{1}\right)$, Calcium chloride $\left(\mathrm{X}_{2}\right)$ with \% drug entrapment efficiency of pantoprazole sodium (Y1)

Table 1.6: Actual Vs predicted value by ANOVA analysis

\begin{tabular}{llll}
\hline Standard & Actual & Predicted & Residual \\
\hline Order & Value & Value & -4.59434 \\
\hline 1 & 76.3734 & 80.96774 & -1.63586 \\
2 & 83.184 & 84.81986 & -0.70339 \\
3 & 87.9686 & 88.67199 & -2.77958 \\
4 & 58.5852 & 61.36478 & 4.258892 \\
5 & 83.48053 & 79.22163 & -10.5615 \\
6 & 86.517 & 97.07848 & -10.606 \\
7 & 31.1558 & 41.76183 & 10.38752 \\
8 & 84.01093 & 73.6234 & -6.71508 \\
9 & 98.7699 & 105.485 & -23.7516 \\
10 & 55.47 & 79.22163 & 14.49954 \\
11 & 93.72117 & 79.22163 & 18.2523 \\
13 & 97.47394 & 79.22163 & 13.94915 \\
\hline
\end{tabular}

Table 1.7: ANOVA for response surface factorial model: analysis of variance table of Ketoprofen drug entrapment efficiency

\begin{tabular}{|c|c|c|c|c|c|}
\hline Anova & SS & DF & MS & F-value & P-value \\
\hline Model & 1533.693 & 3 & 511.231 & 5.518152 & significant \\
\hline Sodium Alginate Conc. (X1) & 841.8526 & 1 & 841.8526 & 9.086831 & 0.0146 \\
\hline B-Calcium Chloride Conc.(X2) & 303.5476 & 1 & 303.5476 & 3.276448 & 0.1037 \\
\hline $\mathrm{AB}$ & 388.2929 & 1 & 388.2929 & 4.191176 & 0.0709 \\
\hline Residual & 833.8081 & 9 & 92.64534 & & \\
\hline Adjusted $\mathrm{R}^{2}$ & 0.530415 & & & & \\
\hline Standard Deviation & 9.625245 & & & & \\
\hline Coefficient of Variance (\%) & 15.82291 & & & & \\
\hline
\end{tabular}




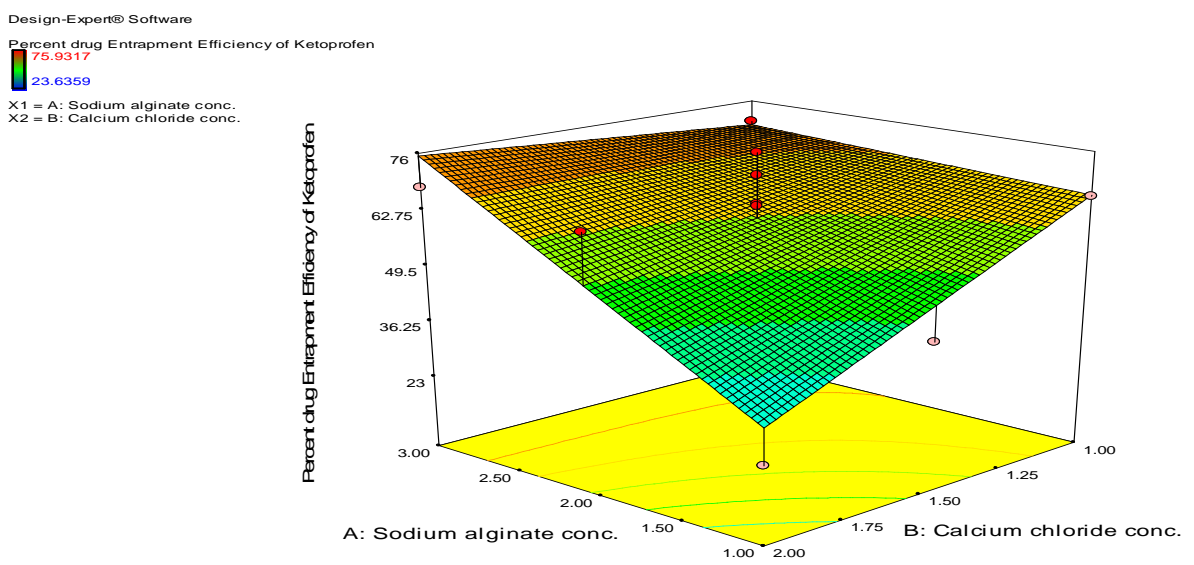

Fig. 1.2: Percentage drug entrapment efficacy of Ketoprofen

\section{Final factorial equation for the process}

$$
Y=\beta_{0}+\beta_{1} \cdot X_{1}-\beta_{2} \cdot X_{2}+\beta_{3} \cdot X_{1} \cdot X_{2}
$$

\% Drug Entrapment Efficiency of Ketoprofen

$$
\begin{aligned}
& =60.831+11.8452 . X_{1}-7.112 . X_{2} \\
& +9.852 \cdot X_{1} \cdot X_{2}
\end{aligned}
$$

3D Surface Response Graph between Sodium alginate $\left(\mathrm{X}_{1}\right)$, Calcium chloride $\left(\mathrm{X}_{2}\right)$ with \% Drug Content of Ketoprofen (Y1)

\section{Determination of percent yield and drug entrapment efficiency}

Beads (100 mg) were crushed in a glass mortar and suspended in 20 $\mathrm{ml}$ of $0.1 \mathrm{~N} \mathrm{HCl}$. After $24 \mathrm{~h}$, the solution was filtered through $0.45 \mathrm{~mm}$ membrane filter, and the filtrate was analyzed for drug content [14].

$$
\text { Drug entrapment efficiency }=\frac{\text { Practical drug content }}{\text { Theoretical drug content }} \times 100
$$

\section{Buoyancy test}

The buoyancy of the beads is study at $37 \pm 0.5^{\circ} \mathrm{C}$, soaking 100 beads in $100 \mathrm{ml}$ of $0.1 \mathrm{HCl}$ at $\mathrm{pH} 1.2$. The number of floating beads is evaluated at fixed time intervals. The floating time is considered as the time at which the $100 \%$ of beads floated. All the data are the average of at least three determinations [15]

\section{Scanning electron microscopy}

The samples were coated with a thin gold layer by a sputter coater unit (SPI, sputter, USA). Then, SEM photographs were taken by a scanning electron microscope (Joel JSM 5400LV SEM, Japan) operated at an acceleration voltage of $15 \mathrm{kV}[16]$. The morphological evaluation of the optimized beads formulation was done by scanning electron microscopy. SEM study revealed that the microspheres were almost spherical in shape with a rough outer surface.
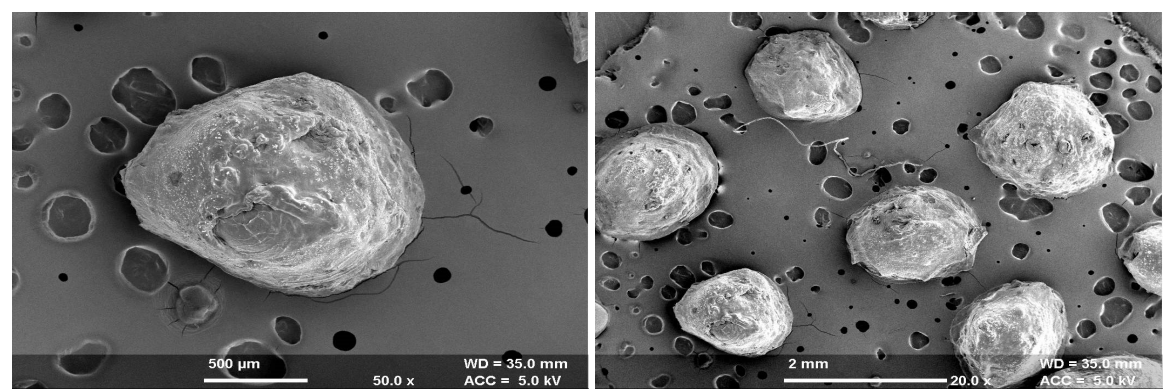

Fig. 1.3: Shape and size of the beads

The scanning electron microscopy (SEM) image of the beads has been used to examine surface topography, the texture and morphology of fractured surfaces are compared to hypothesize the mechanism of drug release and floating.

\section{Differential scanning calorimetry (DSC) studies}

Differential Scanning Calorimetry (DSC) is a useful tool to monitor the effect of additives on the structure of a material and to obtain information about the physicochemical interaction between drug and polymer. Differential Scanning Calorimetry (DSC) of drugs, polymer and statistically optimized formulation were carried out using a Mettler Toledo Star SW 8.10, Model no: DSC 822 instrument. In this process, samples (8-10 $\mathrm{mg}$ ) were weighed into aluminum pans and heated under nitrogen from 5 to $250^{\circ} \mathrm{C}$ [17].

\section{X-ray diffraction (XRD) studies}

To understand the crystalline state of the drug in the polymer matrix, the X-ray diffraction pattern of drug-loaded beads was performed and compared with that of pure drug. Powder forms of the samples were exposed to Cu radiation $(30 \mathrm{kv} \times 15 \mathrm{~mA})$ in a wideangle X-ray diffractometer (Miniflex gonio Meter, Japan). The instrument was operated in continuous mode in increments of 1 $\%$ min and scanned over a $2 \theta$ range of 10 to $90{ }^{\circ} \mathrm{C}$ [18].

\section{In vitro drug release studies}

The in vitro drug release studies of different formulations (Formulation-2 and Formulation-9) and pure drugs were conducted to ensure the effect of sodium alginate concentration and calcium chloride concentration on the release of Pantoprazole Sodium and Ketoprofen from the formulations. The in vitro dissolution studies of the floating formulations were carried out using USP dissolution test apparatus I (basket method). The basket of USP dissolution test apparatus I, each containing a number of beads equivalent to $40 \mathrm{mg}$ Pantoprazole Sodium and $100 \mathrm{mg}$ Ketoprofen, were rotated at 100 $\mathrm{rpm}$ in $900 \mathrm{ml}$ of $0.1 \mathrm{~N} \mathrm{HCl}$ maintained at $37^{\circ} \mathrm{C} \pm 0.5^{\circ} \mathrm{C}$. An aliquot of $5 \mathrm{ml}$ of the solution was withdrawn at predetermined time intervals. 


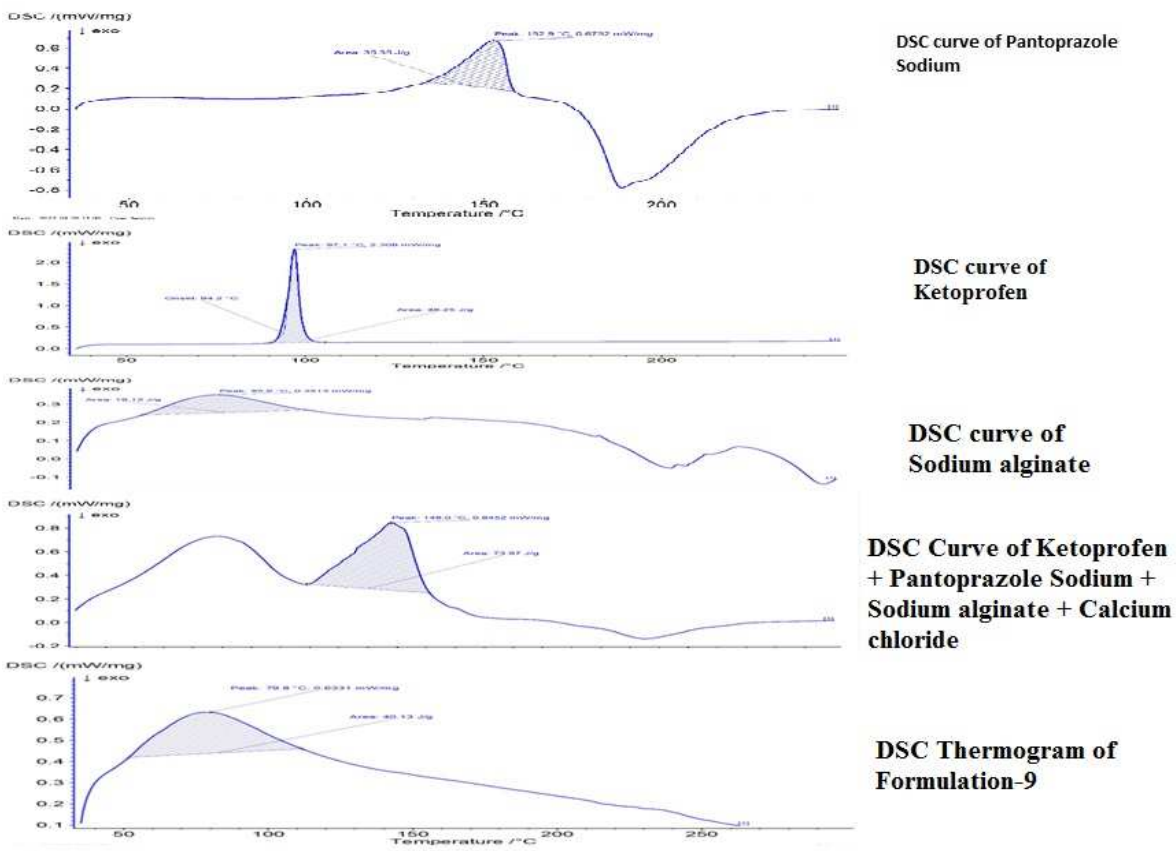

Fig. 1.4: DSC curve of pantoprazole sodium, DSC curve of Ketoprofen, DSC curve of Sodium alginate, DSC curve of Ketoprofen+Pantoprazole Sodium+Sodium Alginate+Calcium chloride, DSC Thermogram of optimized formulation

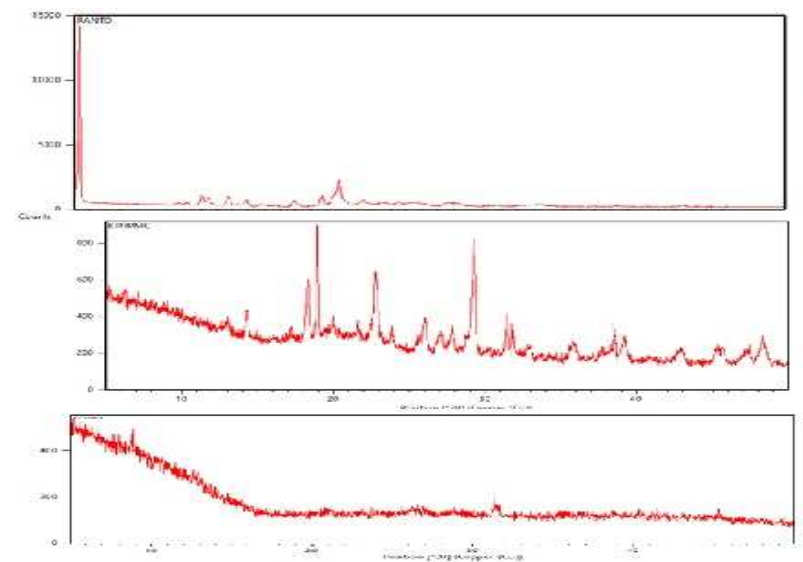

\author{
XRD of Pantoprazole \\ Sodium \\ XRD of physical mixture
}

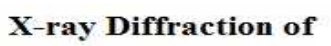

optimized formulation

Fig. 1.5: XRD of pantoprazole sodium, XRD of the physical mixture, X-ray diffraction of optimized formulation

Table 1.8: Percentage drug release of formulations

\begin{tabular}{lllllll}
\hline Time (H) & Pure drug & & Formulation-2 (F2) & & Formulation-9 (F9) \\
\cline { 2 - 6 } & $\begin{array}{l}\text { \%DR pantoprazole } \\
\text { sodium }\end{array}$ & $\begin{array}{l}\text { \% DR } \\
\text { ketoprofen }\end{array}$ & $\begin{array}{l}\text { \%DR pantoprazole } \\
\text { sodium }\end{array}$ & $\begin{array}{l}\text { \% DR } \\
\text { ketoprofen }\end{array}$ & $\begin{array}{l}\text { \%DR pantoprazole } \\
\text { sodium }\end{array}$ & $\begin{array}{l}\text { \% DR } \\
\text { ketoprofen }\end{array}$ \\
\hline 0.25 & $29.79 \pm 0.24$ & $28.66 \pm 0.31$ & $16.29 \pm 0.20$ & $14.10 \pm 0.31$ & $15.82 \pm 0.40$ & $11.51 \pm 0.39$ \\
0.5 & $41.89 \pm 0.32$ & $39.24 \pm 0.17$ & $25.04 \pm 0.14$ & $23.35 \pm 0.15$ & $31.64 \pm 0.13$ & $21.62 \pm 0.36$ \\
1 & $68.86 \pm 0.13$ & $52.63 \pm 0.18$ & $35.37 \pm 0.18$ & $30.08 \pm 0.16$ & $40.01 \pm 0.12$ & $28.43 \pm 0.27$ \\
2 & $75.39 \pm 0.21$ & $68.61 \pm 0.27$ & $43.74 \pm 0.16$ & $37.36 \pm 0.22$ & $48.40 \pm 0.23$ & $44.88 \pm 0.28$ \\
3 & $77.25 \pm 0.11$ & $69.08 \pm 0.32$ & $53.98 \pm 0.15$ & $46.29 \pm 0.32$ & $61.43 \pm 0.15$ & $53.34 \pm 0.14$ \\
4 & & & $62.35 \pm 0.37$ & $52.63 \pm 0.41$ & $69.81 \pm 0.22$ & $64.38 \pm 0.23$ \\
5 & & & $67.01 \pm 0.26$ & $60.62 \pm 0.22$ & $76.33 \pm 0.26$ & $72.37 \pm 0.15$ \\
6 & & & $79.11 \pm 0.41$ & $67.67 \pm 0.27$ & $82.85 \pm 0.28$ & $84.11 \pm 0.26$ \\
7 & & $84.69 \pm 0.20$ & $70.72 \pm 0.28$ & $86.57 \pm 0.21$ & $85.76 \pm 0.33$ \\
8 & & $87.48 \pm 0.38$ & $72.60 \pm 0.29$ & $90.29 \pm 0.11$ & $88.34 \pm 0.25$ \\
9 & & & $88.41 \pm 0.11$ & $73.07 \pm 0.21$ & $93.09 \pm 0.32$ & $91.40 \pm 0.13$ \\
10 & & & $93.99 \pm 015$ & $73.78 \pm 0.23$ & $96.81 \pm 0.22$ & $95.86 \pm 0.11$ \\
11 & & & $93.99 \pm 0.7$ & $74.01 \pm 0.32$ & $96.81 \pm 0.21$ & $96.57 \pm 0.21$ \\
12 & & & $95.85 \pm 0.37$ & $74.48 \pm 0.16$ & $97.74 \pm 0.15$ & $96.57 \pm 0.18$ \\
\hline
\end{tabular}

DR: Drug release, Data from each response is presented in mean $\pm \mathrm{SD}(\mathrm{n}=3)$ 


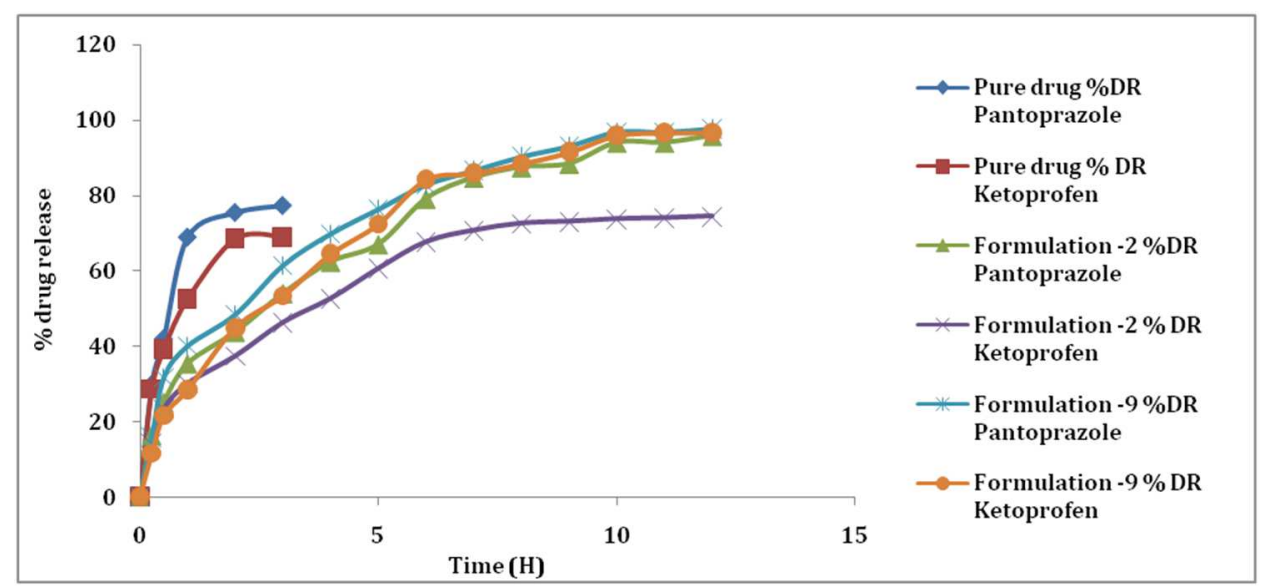

Fig. 1.6: In vitro drug release of different optimized formulations and pure drug in $0.1 \mathrm{~N} \mathrm{HCl}$

Discussion: Prepared floating beads shows almost spherical in shape with the rough outer surface, but high loaded beads were not smooth as low drug-loaded beads as their surface was covered by drug crystals. Differential Scanning Calorimetry (DSC) therms showed relatively broad melting endothermic peak, indicate that only a small fraction of drugs substance existed in the crystalline state. A small sized particle leads to high surface energy, which creates an energetically suboptimal state causing a decrease in the melting point. X-ray diffraction analysis showed the stable character of drug in the drug-loaded hollow beads and revealed the absence of any drug-polymer interactions. X-ray diffraction (XRD) indicates the amorphous dispersion of the drug after entrapment into microbeads may increase the bioavailability of drugs. The optimized formulation F9 showed $97.74 \%$ and $96.57 \%$ drug release for Pantoprazole sodium and ketoprofen, respectively, optimized formulation indicated goof floating characteristics. The in vitro dissolution studies of the formulation formulation-9 shows maximum percent cumulative release with in $12 \mathrm{~h}$. This shows that Formulation- 9 was having the good sustained release of the Pantoprazole Sodium and Ketoprofen up to the $12 \mathrm{~h}$.

\section{CONCLUSION}

In the present study, a satisfactory attempt has been made to formulate gastroretentive floating beads of Pantoprazole sodium and Ketoprofen. From the experimental study result, it was concluded that optimized batch showed good micromeritic properties, entrapment efficiency and releases drug slowly and completely for $12 \mathrm{~h}$ as beads remain in floating condition throughout dissolution study that assures prepared formulation remain floated in stomach without its early passing to lower GIT side. This will help to increase the residence time of Pantoprazole sodium and Ketoprofen in stomach and achieve sustained release thereby increase the bioavailability of drugs. Finally the prepared floating beads may prove to be potential gastroretentive delivery system for safe and effective controlled release for an extended period of time.

\section{FUNDING}

Nil

\section{AUTHORS CONTRIBUTIONS}

All the authors have contributed equally.

\section{CONFLICT OF INTERESTS}

Declared none

\section{REFERENCES}

1. Badoni A, Ojha A, Nanarajan G, Kothiyal GP. Review on gastro retentive drug delivery system. Pharm Innov 2012;8:32-42.
2. Sandhya P, Farhath A, Benazir F, Durani HZ. A review on the gastro retentive drug delivery system of helicobacter pylori. Int J Pharma Res Rev 2013;3:403-22.

3. Badoni A, Ojha A, Nanarajan G, Kothiyal GP. Review on gastro retentive drug delivery system. Pharm Innov 2012;8:32-42.

4. Kumar PR, Doddayya H, Reddy SR. Floating tablets for Helicobacter pylori-induced peptic ulcer therapy: a research review on formulation studies, in vitro and in vivo evaluation. J Biomed Pharm Res 2012;1:39-52.

5. Prajapati ST, Patel LD, Patel DM. Gastric floating matrix tablets: Design and optimization using a combination of polymers. Acta Pharm 2008;58:221-9.

6. Dixit N. Floating drug delivery system. J Curr Pharm Res 2011;7:6-20.

7. Lewis GA, Mathieu D, Phan-Tan-Luu R. Pharmaceutical experimental design, Marcel Dekker; 1961.

8. Singh B, Ahuja N. Book review on pharmaceutical experimental design; 1999.

9. Nelson KG, Wang LY. Determination of time course of tablet disintegration II: Method using continuous functions. J Pharm Sci 1978;67:86-9.

10. Singh B, Dahiya M, Saharan V, Ahuja N. Optimizing drug delivery systems using systematic "design of experiments." Part II: retrospect and prospects. Crit Rev Ther Drug Carrier Syst 2005;22:215-94.

11. Singh B, Mehta G, Kumar R, Bhatia A, Ahuja N, Katare OP. Design, development and optimization of nimesulide-loaded liposomal systems for topical application. Curr Drug Delivery 2005;2:143-53.

12. Aberturas MR, Molpeceres J, Guzmian M, Garclia F. J Microen; 2002. p. 61-72.

13. Patel N, Lalwani D, Gollmer S, Injeti E, Sari Y, Nesamony J. Development and evaluation of a calcium alginate based oral ceftriaxone sodium formulation. Prog Biomater 2016;5:117-33.

14. Nappinnai M, Sivaneswari S. Formulation optimization and characterization of gastroretentive cefpodoxime proxetil mucoadhesive microspheres using $3^{2}$ factorial design. J Pharm Res 2013;7:304-9.

15. Bulgarelli E, Forni F, Bernabei MT. Effect of matrix composition and process conditions on casein-gelatin beads floating properties. Inter J Pharm 2000;198:157-65.

16. El-Badry M, Fetih G, Fathy M. Improvement of solubility and dissolution rate of indomethacin by solid dispersions in Gelucire 50/13 and PEG4000. Sau Pharm J 2009;17:217-25.

17. Srikanthn MV, Rao NS, Sunil SA, Ram BJ, Kolapalli VRM. Statistical design and evaluation of a propranolol $\mathrm{HCl}$ gastric floating tablet. Acta Pharm Sin B 2012;2:60-9.

18. Mandal S, Kumar SS, Krishnamoorthy B, Sanat Kumar Basu SK. Development and evaluation of calcium alginate beads prepared by sequential and simultaneous methods. Braz J Pharm Sci 2010;46:785-93. 